\title{
Corrigendum to "Multivariable Model Reference Adaptive Control of an Industrial Power Boiler Using Recurrent RBFN"
}

\author{
Jafar Tavoosi $\left(\mathbb{D},{ }^{1}\right.$ Yavar Azarakhsh $\left(\mathbb{D},{ }^{1}\right.$ Ardashir Mohammadzadeh $\left(\mathbb{D},{ }^{2}\right.$ Saleh Mobayen (iD), \\ Jihad H. Asad (D), ${ }^{4}$ and Rabia Safdar $\mathbb{D}^{5,6}$ \\ ${ }^{1}$ Department of Electrical Engineering, Faculty of Engineering, Ilam University, Ilam, Iran \\ ${ }^{2}$ Department of Electrical Engineering, University of Bonab, Bonab, Iran \\ ${ }^{3}$ Future Technology Research Center, National Yunlin University of Science and Technology, Yunlin 64002, Douliu, Taiwan \\ ${ }^{4}$ Department of Physics, Faculty of Applied Sciences, Palestine Technical University, P. O. Box 7, Tulkarm, State of Palestine \\ ${ }^{5}$ Department of Mathematics, Lahore College Women University, Lahore, Pakistan \\ ${ }^{6}$ Department of Mathematics, College of Arts and Sciences, University of Jhang, Jhang, Pakistan
}

Correspondence should be addressed to Jafar Tavoosi; j.tavoosi@ilam.ac.ir and Saleh Mobayen; mobayens@yuntech.edu.tw

Received 11 November 2021; Accepted 11 November 2021; Published 11 December 2021

Copyright (c) 2021 Jafar Tavoosi et al. This is an open access article distributed under the Creative Commons Attribution License, which permits unrestricted use, distribution, and reproduction in any medium, provided the original work is properly cited.

In the article titled "Multivariable Model Reference Adaptive Control of an Industrial Power Boiler Using Recurrent RBFN" [1], there were errors in Figures 1 and 3, which should be corrected as follows.
Additionally, "RBFN-based" in the abstract should be corrected to "radial-basis function neural network (RBFN)." On page 1 of the Introduction, "PID" should be corrected to "proportional-integral-derivative (PID)." 


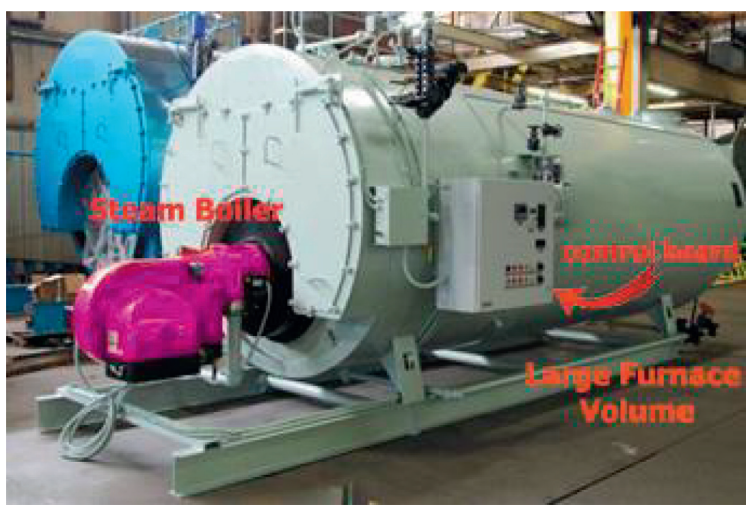

Figure 1: A power plant boiler.

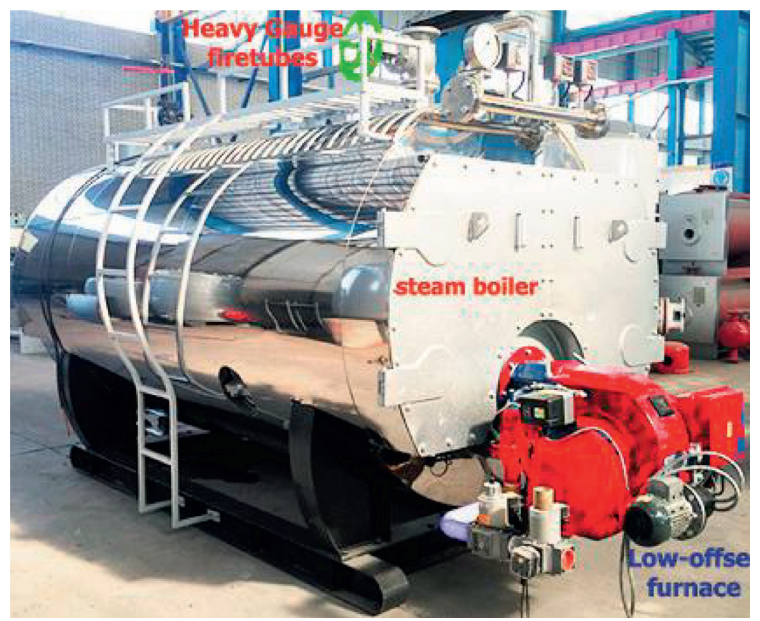

Figure 3: The industrial boiler.

\section{References}

[1] J. Tavoosi, Y. Azarakhsh, A. Mohammadzadeh, S. Mobayen, J. H. Asad, and R. Safdar, "Multivariable model reference adaptive control of an industrial power boiler using recurrent RBFN," Complexity, vol. 2021, Article ID 5451439, 12 pages, 2021. 